Research Article

\title{
Computation Method for the Settlement of a Vertically Loaded Pile in Sloping Ground
}

\author{
Chong Jiang $(D$, Wen-yan Wu, Jia-li He, and Lu-jie Chen \\ School of Resources and Safety Engineering, Central South University, Changsha 410083, Hunan, China \\ Correspondence should be addressed to Chong Jiang; jiang4107@sohu.com
}

Received 16 February 2020; Accepted 16 June 2020; Published 23 July 2020

Academic Editor: Xihong Zhang

Copyright (C) 2020 Chong Jiang et al. This is an open access article distributed under the Creative Commons Attribution License, which permits unrestricted use, distribution, and reproduction in any medium, provided the original work is properly cited.

\begin{abstract}
Based on the hyperbolic curve tangent modulus method and the wedge stress theory, this paper proposes a calculation method for the settlement of a vertically loaded single pile in sloping ground. By establishing the relationship between the initial tangent modulus and the compression modulus of the slope soil, the tangent modulus of the slope soil is obtained combining with Mindlin-Geddes solution and Hansen formula, and the solution of the pile settlement in sloping ground is derived. Then, a series of numerical analyses are carried out to examine the feasibility of the proposed method. Finally, the effect of parameters is discussed in detail, including the slope angle, the distance of the pile from the slope crest, and the soil properties around the pile. The results show that the pile settlement will increase by increasing the slope angle or decreasing the distance of the pile from the slope crest, and the effect of the two parameters on the pile settlement is coupling-related. Besides, the compression modulus, cohesion, and internal friction angle of the soil around the pile are negatively related to the pile settlement and it is found that the compression modulus of the soil is the more influential parameter.
\end{abstract}

\section{Introduction}

Pile foundations are one of the widely used foundations, which are often used in the transmission tower, high-rise building, bridge engineering, and other structures. These structures are often built in or near the slope. The calculation of the pile settlement is an important part of the pile foundation design in sloping ground [1].

At present, the majority of studies focus on the theoretical calculation methods of the pile settlement in flat ground, mainly including the elastic theory method $[2,3]$, the shearing displacement method [4], the load transfer method [5], and the layerwise summation method. In recent years, based on the above theoretical methods, many researchers have carried out further research on the nonlinear calculation of the pile settlement [6-8]. For example, Zhao et al. [9] used the energy method to calculate the pile settlement with a high bearing platform. According to the cylindrical cavity expansion theory and the load-transfer models, Zhang et al. [10] established the nonlinear deformation calculation method of the pile foundation in sand. In addition, a series of optimization calculation methods of the pile settlement under different conditions in flat ground are proposed [11-13]. However, the pile behavior in sloping ground is different from that in flat ground. First, the stress state of the soil in sloping ground changes because the soil around the pile is in an asymmetric space which is different from the semi-infinite space in flat ground. Second, the lack of soil in a slope reduces the constraint of the soil on the pile and the Earth pressure on the pile side will inevitably decrease; therefore, the ultimate bearing capacity of the pile tip in sloping ground decreases. Finally, the slope effect is generated; that is, the pile displacement in sloping ground is larger than that in flat ground under the same load. As a result, the calculation methods of the pile settlement in flat ground are no longer suitable for piles in sloping ground. However, the research on the calculation method of the pile settlement in sloping ground is limited. Most of the researchers have investigated the lateral response [14-16], lateral deformation $[17,18]$, and lateral bearing capacity [19-21] of pile foundations or the load transfer law of pile foundations under vertical load [22] in sloping ground. 
Therefore, it is necessary to establish the calculation method of the pile settlement in sloping ground.

Based on the hyperbolic curve tangent modulus method, considering the slope effect, this paper establishes the calculation method of the pile settlement in sloping ground and performs parametric studies. Firstly, based on the wedge stress theory, the three-direction stress relationship of soil in sloping ground under the self-weight is studied, and the relationship between the initial tangent modulus $E_{0}$ and the compression modulus $E_{s}$ is deduced. Then, combined with the tip resistance ratio of the pile in sloping ground, Mindlin-Geddes solution is improved to calculate the additional stress of the pile tip. Besides, Hansen formula is used to calculate the ultimate resistance at the pile tip, which can consider the inclination of the ground. Finally, the pile settlement in sloping ground is calculated by combining with the layerwise summation method. In addition, the theoretical results are compared with the numerical simulation results. The influential parameters including the slope angle, the distance of the pile from the slope crest, the compression modulus, cohesion, and internal friction angle of the soil around the pile are analyzed.

\section{Calculation Method of the Pile Settlement in Sloping Ground Based on the Hyperbolic Curve Tangent Modulus Method}

2.1. Basic Assumptions. The schematic of the model analyzed is illustrated in Figure 1. $(r, \theta)$ is the polar coordinate system, $(x, z)$ is the rectangular coordinate system, and the $y$ direction is perpendicular to the $x-z$ plane. The stress of the soil around the pile under the self-weight is $\rho g$. The basic assumptions are made as follows for simplicity:

(1) The pile is rigid without compression deformation. The settlement at the pile tip is equal to the settlement at the pile top.

(2) Both soil and pile are homogeneous and isotropic.

(3) The slope is stable without instability and damage.

2.2. Calculation Method of the Pile Settlement in Sloping Ground. Based on the hyperbolic curve tangent modulus method [23], the load-settlement curve of the pile is assumed to be a hyperbolic curve:

$$
P=\frac{S}{a+b S}
$$

where $a$ and $b$ are fitting parameters of the hyperbolic curve, which can be obtained by curve fitting.

Then the tangent modulus of the soil at any depth under the pile tip is

$$
E_{t}=\left(1-R_{f} \frac{P_{z}}{P_{u}}\right)^{2} E_{0}
$$

Combined with the layerwise summation method, it can be obtained that, under the load increment $P_{i}$, the compression $\Delta S_{i j}$ of the soil layer $\Delta h_{j}$ at a certain depth under the pile is

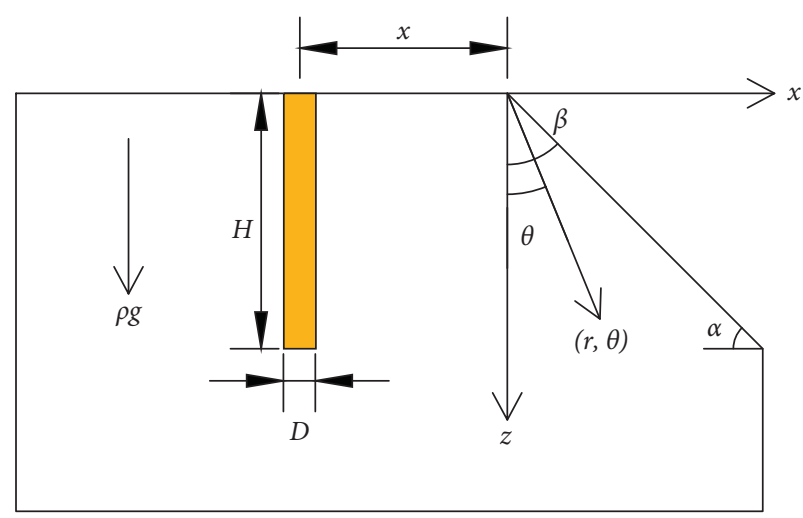

FIGURE 1: Schematic view of the model.

$$
\Delta S_{i j}=\frac{P_{i} \Delta h_{j}}{E_{t}} .
$$

After obtaining the compression of each layered soil, the total settlement $S_{i}$ of the pile tip under each load level can be obtained:

$$
S_{i}=\sum_{j=1}^{n} \Delta S_{i j}
$$

In order to consider the slope effect on the pile settlement, based on the wedge stress theory, the initial tangent modulus equation of the soil in a slope is derived. Then, by introducing Mindlin-Geddes solution and Hansen formula, the tangent modulus of the pile in sloping ground is obtained according to equation (2), and the calculation method of the pile settlement in sloping ground is finally established by combining equation (3) with equation (4).

2.2.1. Initial Tangent Modulus Equation of the Pile in Sloping Ground Based on Wedge Theory. In order to study the threedimensional stress relationship of the soil in a slope, the elastic stress solution of the soil in a slope under the selfweight in [24] is introduced:

$$
\begin{aligned}
\sigma_{r}= & \frac{1}{4} \rho g r\left[\frac{3 \cos ^{2} \beta-2}{\cos ^{2} \beta}(\cos \theta-\cos 3 \theta)+\operatorname{tg} \beta(\sin \theta-3 \sin 3 \theta)\right] \\
& +\rho g r \cos \theta,
\end{aligned}
$$

$$
\begin{aligned}
\sigma_{\theta}= & \frac{1}{4} \rho g r\left[\frac{3 \cos ^{2} \beta-2}{\cos ^{2} \beta}(3 \cos \theta+\cos 3 \theta)+\operatorname{tg} \beta(\sin \theta\right. \\
& +3 \sin 3 \theta)]+\rho g r \cos \theta, \\
\tau_{r \theta}= & \frac{1}{4} \rho g r\left[\frac{3 \cos ^{2} \beta-2}{\cos ^{2} \beta}(\sin \theta+\sin 3 \theta)+\operatorname{tg} \beta(\cos \theta+3 \cos 3 \theta)\right],
\end{aligned}
$$

where $\sigma_{r}, \sigma_{\theta}$, and $\tau_{r \theta}$ are the elastic stress solutions of the soil in the polar coordinate system. 
Equations (5) (7) in the polar coordinate are transformed to elastic stress solution in rectangular coordinate system as equations (8) (10) for simplicity:

$$
\begin{aligned}
\sigma_{z} & =\frac{\sigma_{r}+\sigma_{\theta}}{2}+\frac{\sigma_{r}-\sigma_{\theta}}{2} \cos 2 \theta-\tau_{r \theta} \sin 2 \theta, \\
\sigma_{x} & =\frac{\sigma_{r}+\sigma_{\theta}}{2}-\frac{\sigma_{r}-\sigma_{\theta}}{2} \cos 2 \theta+\tau_{r \theta} \sin 2 \theta, \\
\tau_{z x} & =\frac{\sigma_{r}-\sigma_{\theta}}{2} \sin 2 \theta+\tau_{r \theta} \cos 2 \theta,
\end{aligned}
$$

where $\sigma_{z}, \sigma_{x}$, and $\tau_{z x}$ are the elastic stress solutions of the soil in the rectangular coordinate system.

The soil mass on the central axis of the pile body includes

$$
\begin{aligned}
& r \cos \theta=z, \\
& r \sin \theta=x .
\end{aligned}
$$

In the rectangular coordinate system, the elastic stress solution of the soil in a slope under the self-weight stress can be obtained by equations (5) (12):

$$
\begin{aligned}
\sigma & =\rho g z \\
\sigma_{x} & =-\rho g\left(z \frac{2 \cos ^{2} \beta-2}{\cos ^{2} \beta}+x \operatorname{tg} \beta\right), \\
\tau_{z x} & =\rho g z \operatorname{tg} \beta .
\end{aligned}
$$

According to equation (16), which is the principal stress transformation equation, the maximum principal stress $\sigma_{1}$ and the minimum principal stress $\sigma_{2}$ can be obtained:

$$
\left.\begin{array}{c}
\sigma_{1} \\
\sigma_{1}
\end{array}\right\}=\frac{\sigma_{z}+\sigma_{x}}{2} \pm \sqrt{\left(\frac{\sigma_{z}-\sigma_{x}}{2}\right)^{2}+\tau_{z x}^{2}}
$$

Suppose that this is a plane strain problem and the longitudinal strain $\sigma_{x}=k_{1} \sigma_{z}$, combined with Hooke's law:

$$
\varepsilon_{y}=\frac{1}{E_{0}}\left[\sigma_{y}-v\left(\sigma_{z}+\sigma_{x}\right)\right] \text {. }
$$

The third principal stress can be calculated:

$$
\sigma_{y}=v\left(\sigma_{z}+\sigma_{x}\right)
$$

Therefore, based on equations (13) (18), the three-dimensional stress solution of soil in a slope can be obtained. The three-dimensional stress relationship of soil in a slope under self-weight is expressed in equations (19) and (20).

$$
\begin{aligned}
& \sigma_{x}=k_{1} \sigma_{z}, \\
& \sigma_{y}=k_{2} \sigma_{z},
\end{aligned}
$$

where $k_{1}$ and $k_{2}$ are the ratio of horizontal stresses $\sigma_{x}$ and $\sigma_{y}$ and vertical stress $\sigma_{z}$.
In the confining compression test, the relationship between soil stress, strain, and compression modulus $E_{s}$ is as follows:

$$
\varepsilon_{z}=\frac{\sigma_{z}}{E_{s}}
$$

Under the condition of triaxial test, according to the generalized Hooke's law, the vertical strain of soil is as follows:

$$
\varepsilon_{z}=\frac{\sigma_{z}}{E_{0}}-v \frac{\sigma_{x}}{E_{0}}-v \frac{\sigma_{y}}{E_{0}} .
$$

Assuming that the initial state of the soil is the same under different test conditions [25], the relationship between the initial tangent modulus $E_{0}$ and the compression modulus $E_{s}$ can be obtained by combining equations (21) and (22), that is, the initial tangent modulus equation of the pile in sloping ground:

$$
E_{0}=E_{s}\left(1-v k_{1}-v K_{2}\right) .
$$

2.2.2. Additional Stress Solution of the Soil at the Pile Tip. In order to consider the slope effect on the additional stress of the soil at the pile tip, the resistance ratio $\delta$ (end resistance ratio $\delta=$ pile end resistance/pile top load) of the pile tip in sloping ground is introduced to improve the MindlinGeddes solution [26]. In this solution, the vertical load $P$ on the pile top is divided into two parts: the pile end resistance $\delta P$ and the pile side friction $(1-\delta) P$. It is assumed that pile side friction resistance is a triangular distribution with linear increase along the pile depth, as shown in Figure 2.

Then the additional stress of the soil under the pile tip is produced by the pile tip resistance and the pile side friction resistance:

$$
p_{z}=p_{z p}+p_{z s}
$$

The pile tip resistance and pile side friction are assumed to be the internal concentrated force of soil, and the additional stress produced by the pile tip resistance is

$p_{z p}=\frac{\delta P}{H^{2}} I_{p}$

$$
\begin{aligned}
I_{p}= & \frac{1}{8 \pi(1-v)}\left\{\frac{(1-2 v)(m-1)}{A^{3}}-\frac{(1-2 v)(m-1)}{B^{3}}\right. \\
& +\frac{3(m-1)}{A^{5}}+\frac{3(3-4 v) m(m+1)^{2}-3(m+1)(5 m+1)}{B^{5}} \\
& \left.+\frac{30 m(m+1)^{3}}{B^{7}}\right\} .
\end{aligned}
$$

The additional stress caused by the pile side friction is 

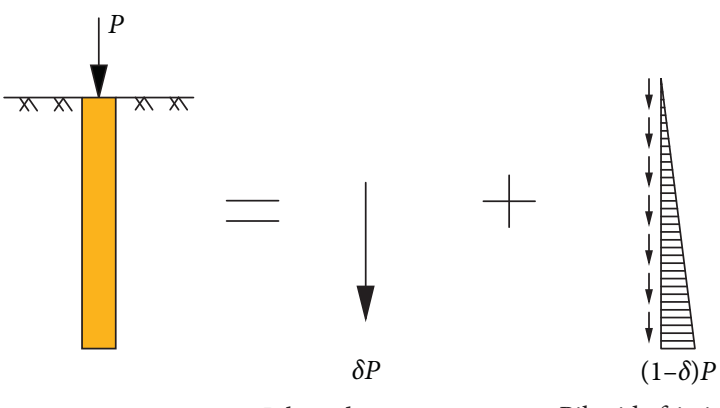

Pile end resistance

Pile side friction with linear increase along the pile depth

Figure 2: Decomposition of pile load in Mindlin-Geddes solution [26].

$$
\begin{aligned}
p_{z s}= & \frac{P}{H^{2}}(1-\delta) I_{s}, \\
I_{s}= & \frac{1}{4 \pi(1-v)}\left\{\frac{2(2-v)}{A}-\frac{2(2-v)(4 m+1)-2(1-2 v)(1+m) m^{2} / n^{2}}{B}-\frac{2(1-2 v) m^{3} / n^{2}-8(2-v) m}{F}\right. \\
& -\frac{m n^{2}+(m-1)^{3}}{A}-\frac{4 v n^{2} m+4 m^{3}-15 n^{2} m-2(5+2 v)(m / n)^{2}(m+1)^{3}}{B^{3}} \\
& -\frac{12(m / n)^{2} m^{5}+6 m^{3}+2(5+2 v)(m / n)^{2} m^{3}}{F^{3}}-\frac{6 m n^{2}\left(n^{2}-m^{2}\right)+12(m / n)^{2}(m+1)^{5}}{B^{5}} \\
& \left.+\frac{12(m / n)^{2} m^{5}+6 m n^{2}\left(n^{2}-m^{2}\right)}{F^{5}}+2(2-v) \operatorname{In}\left(\frac{A+m-1}{F+m} \times \frac{B+m+1}{F+m}\right)\right\}
\end{aligned}
$$

where $A^{2}=n^{2}+(m-1)^{2} ; B^{2}=n^{2}+(m+1)^{2} ; F^{2}=n^{2}+m^{2}$; $n=x / H$; and $m=z / H$.

Therefore, according to equations (24) (28), the additional stress on the soil at any depth of the pile tip under the vertical load $P$ can be calculated. The pile tip resistance ratio $\delta$ is generally determined by the actual measurement data of local engineering [26]. In this paper, the Mindlin-Geddes solution is improved by using the pile tip resistance ratio in sloping ground obtained from numerical simulation.

2.2.3. Solution of the Ultimate Resistance at the Pile Tip. In order to consider the slope effect on the ultimate resistance of the pile tip, Hansen solution [25] is used to calculate the ultimate resistance of the pile tip:

$$
p_{u}=\frac{1}{2} \gamma D N_{r} s_{r} d_{r} g_{r} b_{r}+q N_{q} s_{q} d_{q} i_{q} g_{q} b_{q}{ }_{c} N_{c} s_{c} d_{c} i_{c} g_{c} b_{c} .
$$

In this paper, since load inclination and foundation bottom inclination are not considered, $i_{r}, i_{q}, i_{c}, b_{r}, b_{q}$, and $b_{c}$ are all taken as 1 .

2.3. Determination of Calculation Parameters. The method of parameter determination $[25,26]$ is shown in Table 1 .

\section{Validation of Settlement Calculation Method}

The finite element software is used to simulate the pile settlement under vertical load in sloping ground. By comparing the results of numerical simulation and theoretical calculation, the reliability of the proposed method is verified.

3.1. Numerical Simulation. Most of the available researches are focused on the lateral response of the pile under the lateral load in slopes and the settlement characteristics of the pile under vertical load in slopes are rarely analyzed. Therefore, the data of $\alpha=45^{\circ}$ in [27] was used to verify the correctness of the modeling method. The pile length is $H=12 \mathrm{~m}$ and the pile diameter is $D=0.6 \mathrm{~m}$. Soil and pile properties are summarized in Table 2.

The comparison results between the simulation in this paper and those in [27] are shown in Figure 3. A good compatibility could be seen, which proves the correctness of the numerical modeling method in this paper.

The rigid pile is defined as [28] $H \leq 2.5 / \eta$, where $\eta$ is the deformation coefficient of pile body $\left(\mathrm{m}^{-1}\right)$. The length diameter ratio of pile is calculated by combining the " $\mathrm{m}$ " method. Therefore, in this simulation, $H=8 m, D=1 \mathrm{~m}$, and distance of the pile from the slope crest is the normalized value of $x=(n+0.5) D$. Parameters in Table 2 are used for soil and pile properties. 
TABLE 1: Determination of calculation parameters.

\begin{tabular}{|c|c|c|c|}
\hline Parameters & Determination method & Parameters & Determination method \\
\hline$a, b$ & Obtained from P-S curve fitting & $s_{r}$ & $S_{c}=1-0.4(D / H)$ \\
\hline$R_{f}$ & According to experience value, generally between 0.85 and 1.00 & $s_{q}$ & $S_{q}=1+(D / H) \tan \phi$ \\
\hline $\mathrm{P}, c, v, \gamma, \varphi, E s$ & Determination by laboratory test or field test & $s_{c}$ & $S_{c}=1+0.2(D / H)$ \\
\hline$\delta$ & Statistical determination of measured data of local projects & $g_{c}$ & $g_{c}=1-\left(\alpha / 147^{\circ}\right)$ \\
\hline$N_{q}$ & $N_{q}=e^{\pi \tan \phi} \tan ^{2}\left(45^{\circ}+(\phi / 2)\right)$ & $g_{a}$ & $g_{q}=(1-0.5 \tan \alpha)^{5}$ \\
\hline$N_{c}$ & $N_{c}=\left(N_{q}-1\right) \cot \phi$ & $g_{r}$ & $g_{r}=(1-0.5 \tan \alpha)^{5}$ \\
\hline$N_{r}$ & $N_{r}=1.5\left(N_{q}-1\right) \tan \phi$ & $d_{r}$ & $d_{r}=1.0$ \\
\hline$d_{q}$ & $d q=1+2 \tan \phi\left(1^{1}-\sin \phi\right)^{2}(H / D)$ & $d_{c}$ & $d c=1+0.4(H / D)$ \\
\hline
\end{tabular}

TABLE 2: Soil and pile properties.

\begin{tabular}{lcccccc}
\hline Material & Young's modulus $(\mathrm{Pa})$ & Poisson's ratio & Density $\left(\mathrm{kg} \cdot \mathrm{m}^{-3}\right)$ & Cohesion $(\mathrm{Pa})$ & Friction angle $\left(^{\circ}\right)$ & Dilatation angle $\left(^{\circ}\right)$ \\
\hline Pile & $3.0 \times 10^{10}$ & 0.1 & 2500 & - & - & - \\
Soil & $1.2 \times 10^{7}$ & 0.40 & 1800 & $3.0 \times 10^{4}$ & $35^{\circ}$ & $5^{\circ}$ \\
\hline
\end{tabular}

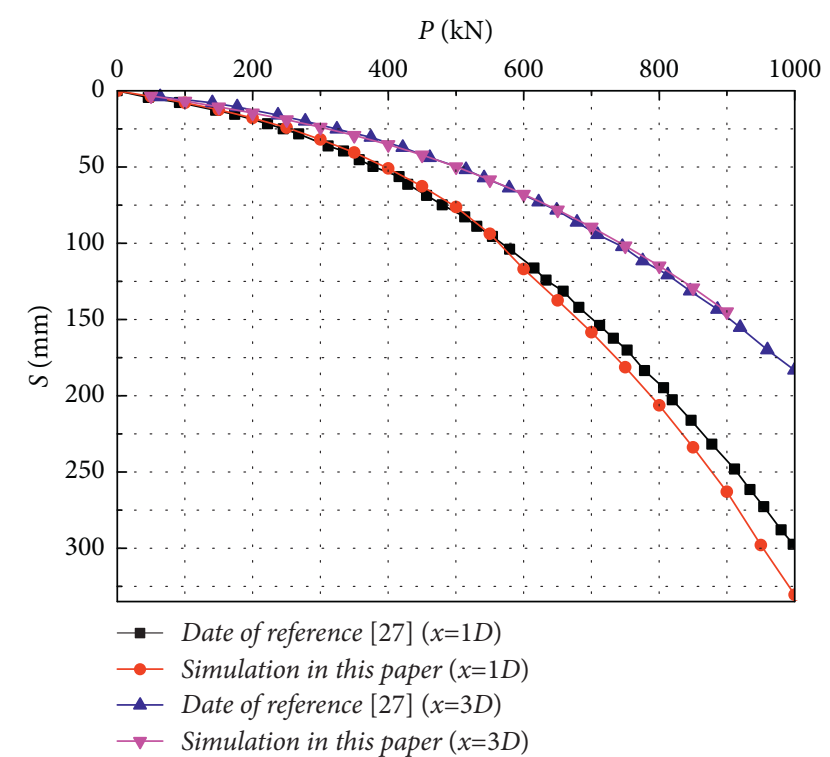

Figure 3: Comparison of simulation results between this paper and literature.

3.2. Validation of the Settlement Calculation Method. The ratio of pile tip resistance and pile top load obtained by numerical simulation is applied to the parameter $\delta$ in theoretical calculation. The comparison between numerical simulation results and theoretical calculation results is shown in Figures 4 and 5.

A good fit of P-S curve could be seen and the settlement law of the pile is consistent. Comparing the settlement of theoretical calculation and simulation results under the same conditions, the maximum error values in Figures 4 and 5 are $8.78 \%$ and $5.65 \%$, respectively, which are within the reasonable error range, proving the correctness of the theoretical calculation method.

\section{Parametric Analysis}

The slope angle, the distance of the pile from the slope crest, the compression modulus, cohesion, and friction angle of



Figure 4: Comparison of P-S curve under $\alpha=15^{\circ}$.

the soil are important parameters that influence the pile settlement in sloping ground. Based on the calculation method of the pile settlement in sloping ground under vertical load, parametric studies are carried out. The values of these parameters are shown in Table 2.

4.1. Effect of the Slope Angle. Figures 6 and 7 show the P-S curve of the pile with 7 different slope angles when the distance of the pile from the slope crest $x$ is $0.5 D$ and $10.5 D$, respectively, which shows the following:

(1) Under the same load, the pile settlement increases with the increase of slope angle. When the slope angle gets larger, the increase of the pile settlement is more obvious. 


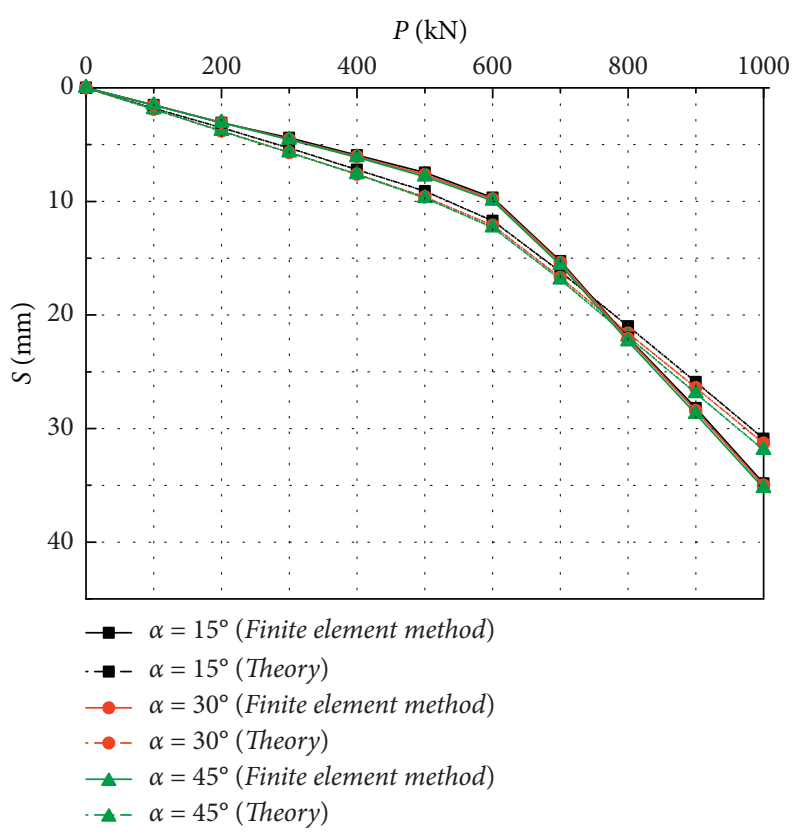

Figure 5: Comparison of P-S curve under $x=10.5 D$.



Figure 6: Effect of slope angle on P-S curve with different slope proximity under $x=0.5 D$.

(2) The effect of slope angle on the pile settlement is weakened by the increase of distance of the pile from the slope crest. When $x=0.5 D$, the growth rate of the pile settlement is between $2.97 \%$ and $40.26 \%$ with the increase of slope angle, compared with that of pile in flat ground under the maximum load. When $x=10.5 D$, the growth rate of the pile settlement is between $1.98 \%$ and $3.63 \%$.

4.2. Effect of the Distance of the Pile from the Slope Crest. Figures 8 and 9 show the P-S curve of the pile under 10 different slope proximities with slope angle of $15^{\circ}$ and $60^{\circ}$, respectively, which shows the following:

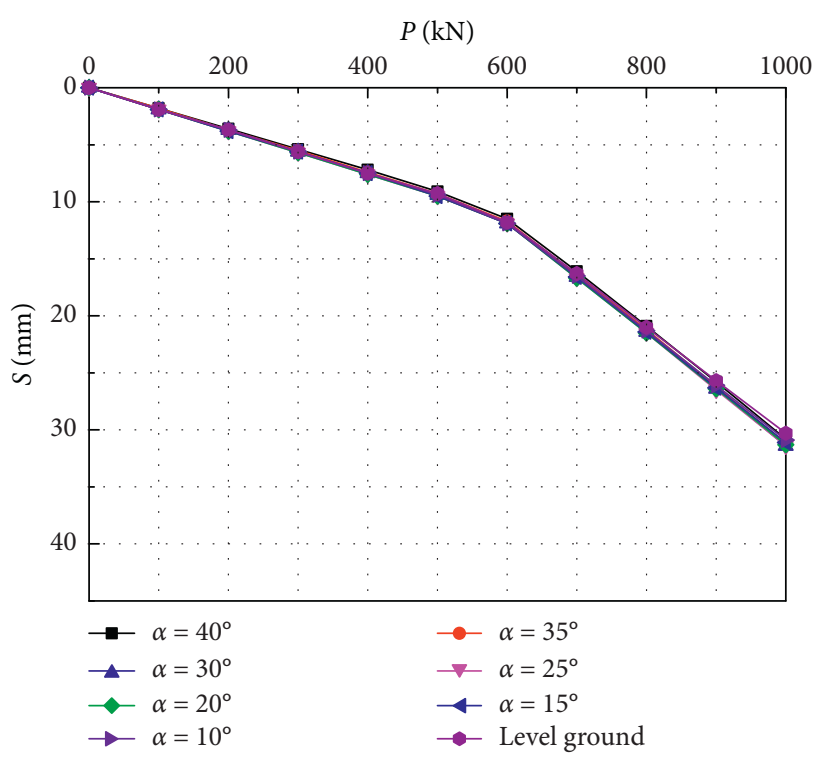

FIgURE 7: Effect of slope angle on P-S curve with different slope proximity under $x=10.5 D$.

(1) With the decrease of slope proximity, the settlement of pile foundation increases gradually under the same load. The smaller the slope proximity is, the more significantly the tendency of pile foundation settlement increases.

(2) With the increase of slope angle, the effect of slope proximity on slope effect is strengthened. Compared with the pile in flat ground, when $\alpha=15^{\circ}$, the growth rate of the pile settlement approaches 0 with the decrease of $x$ and when $\alpha=60^{\circ}$, the maximum growth rate of the pile settlement reaches $47.84 \%$ with the decrease of $x$. 


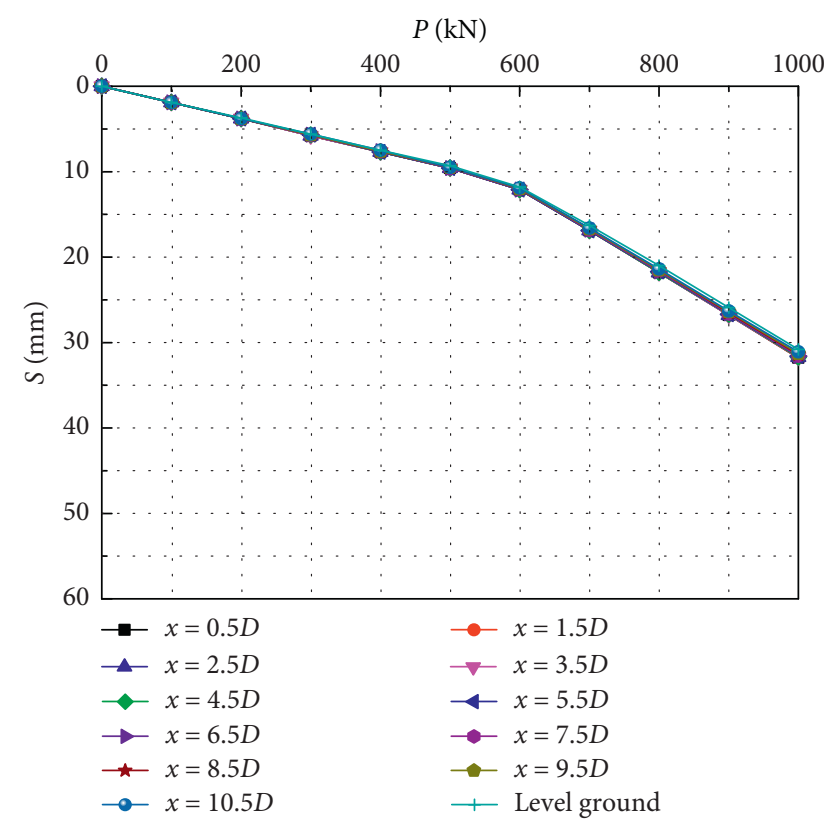

Figure 8: Effect of slope proximity on P-S curve with different slope angle under $\alpha=15^{\circ}$.



FIgURE 9: Effect of slope proximity on P-S curve with different slope angle under $\alpha=60^{\circ}$.

(3) When $x \geq 8.5 D$, the pile settlement tends to be stable, which is very close to the settlement of pile in flat ground, and the effect of slope is negligible.

4.3. Effect of Compression Modulus. Figures 10 and 11 show the $E_{s}-S$ curve under different conditions when $P=1000 \mathrm{kN}$, which shows the following.

The settlement of pile foundation decreases with the increase of compression modulus $E_{s}$, and the decrease range

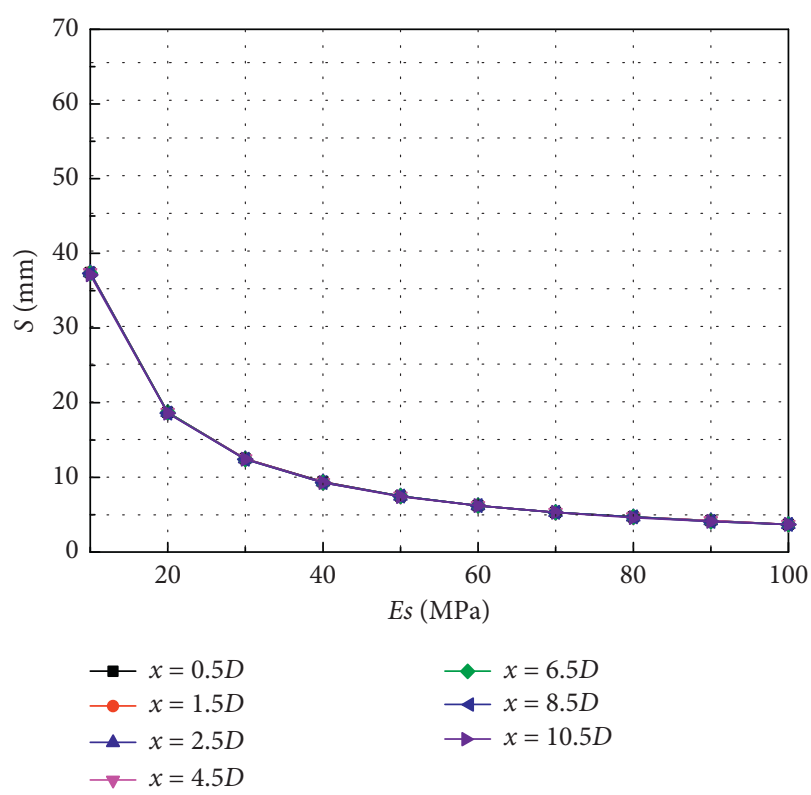

Figure 10: $E_{s}$-S curve under $P=1000 \mathrm{kN}$ and $\alpha=15^{\circ}$.

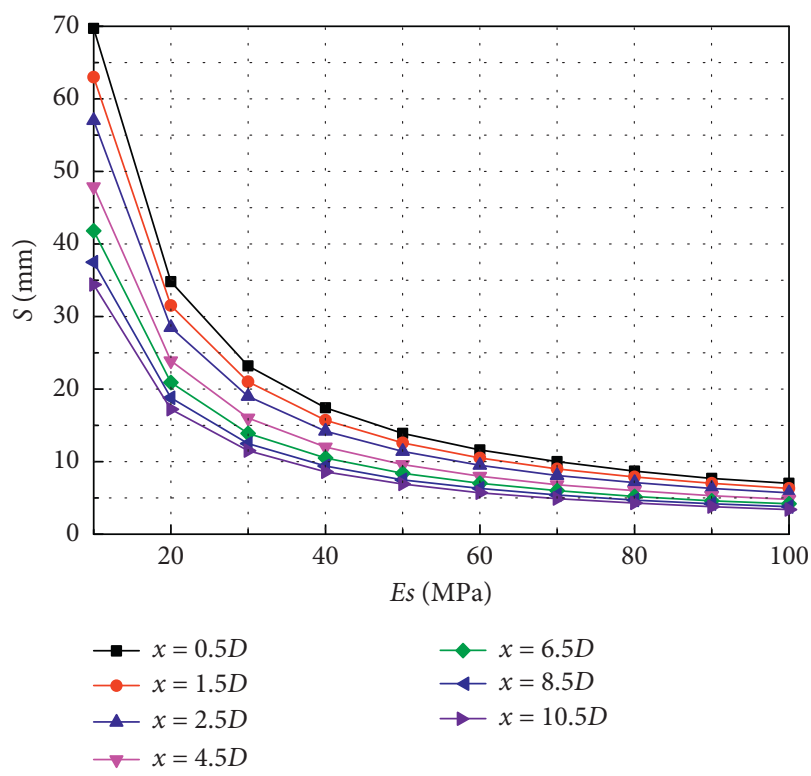

Figure 11: $E_{s}-S$ curve under $P=1000 \mathrm{kN}$ and $\alpha=60^{\circ}$.

is related to slope effect. When $\alpha=15^{\circ}$, with the increase of $E_{s}$ from $10 \mathrm{MPa}$ to $40 \mathrm{MPa}$, the settlement of pile foundation decreases sharply, with the decrease range reaching $74.87 \%$; when $E_{s}$ is between $40 \mathrm{MPa}$ and $60 \mathrm{MPa}$, the rate of settlement decrease gradually slows down; when $E_{s}$ is more than $60 \mathrm{MPa}$, the settlement of pile foundation tends to be stable. However, when $\alpha=60^{\circ}$, the range of pile foundation settlement changes with $E_{s}$ increases with the decrease of $x$, which shows that the more prominent the slope effect, the greater the influence of $E_{s}$ on the settlement of pile foundation. 


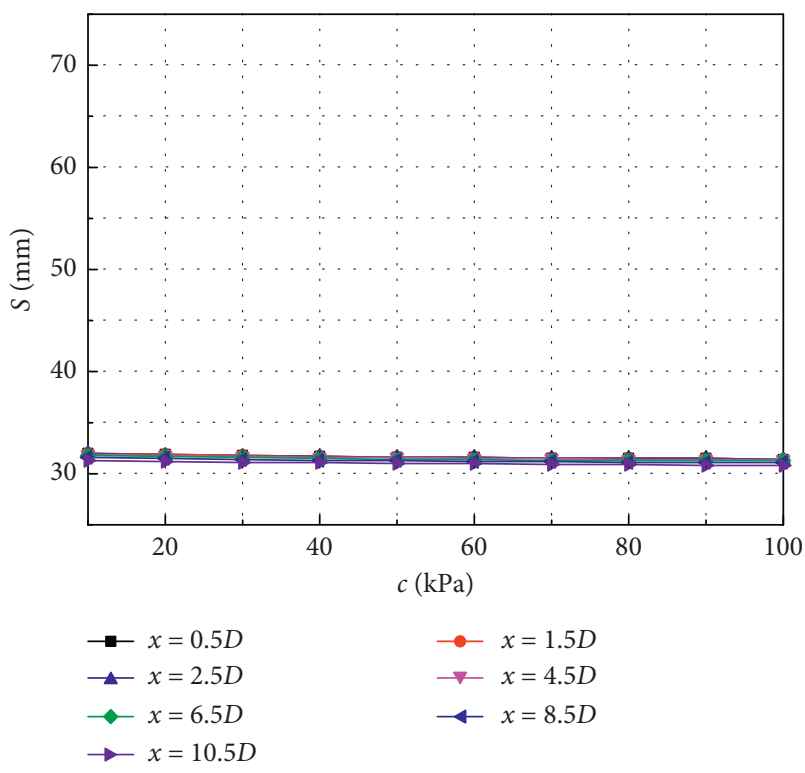

Figure 12: $\mathrm{c}-\mathrm{S}$ curve under $P=1000 \mathrm{kN}$ and $\alpha=15^{\circ}$.

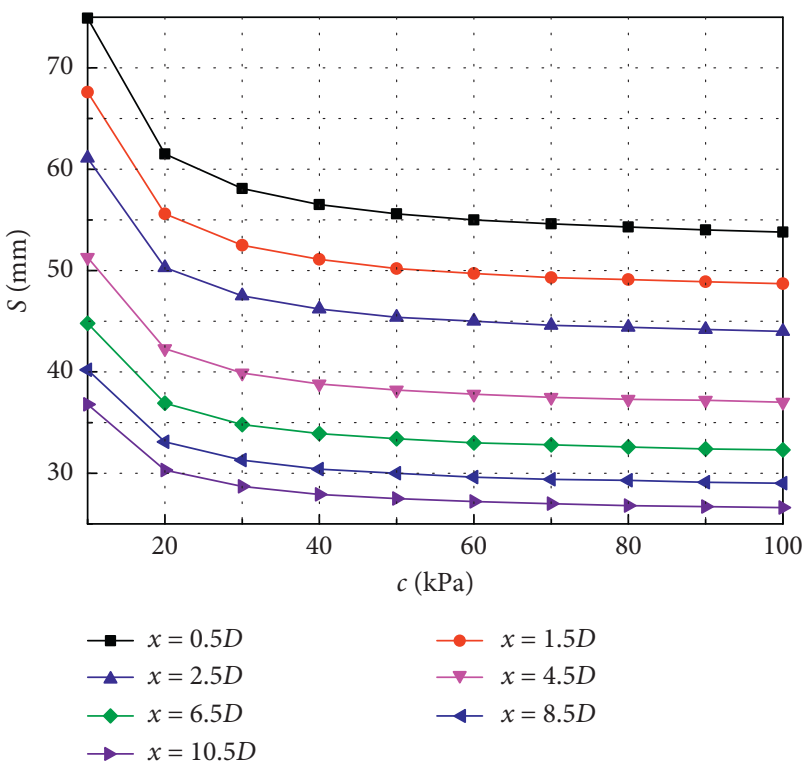

Figure 13: $c-S$ curve under $P=1000 \mathrm{kN}$ and $\alpha=60^{\circ}$.

4.4. Influence of Cohesion. Figures 12 and 13 show the $c-S$ curve under different conditions when $P=1000 \mathrm{kN}$. The pile settlement decreases with the increase of cohesion and the decrease is related to the slope effect. When $\alpha=15^{\circ}$, the variation of the pile settlement with $c$ is very small; however, when $\alpha=60^{\circ}$, with the increase of $c$ from $10 \mathrm{kPa}$ to $20 \mathrm{kPa}$, the pile settlement decreases sharply and the decrease range is between $17.66 \%$ and $17.89 \%$ with the difference of $x$. When $c$ is between $20 \mathrm{kPa}$ and $60 \mathrm{kPa}$, the decrease rate of settlement slows down and when $c$ is over $60 \mathrm{kPa}$, the settlement of pile foundation tends to be stable.

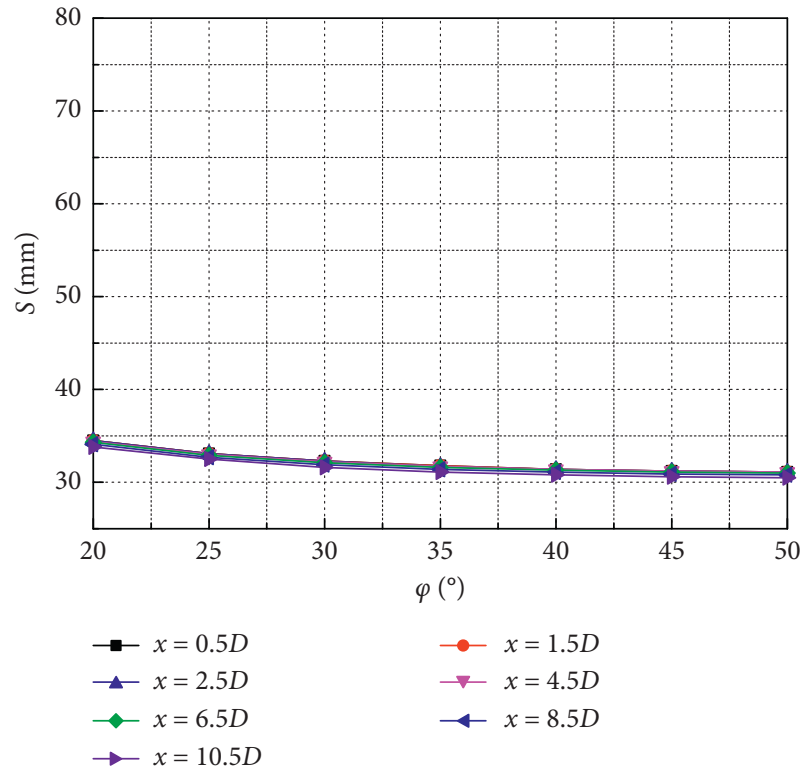

Figure 14: $\varphi$-S curve under $P=1000 \mathrm{kN}$ and $\alpha=15^{\circ}$.

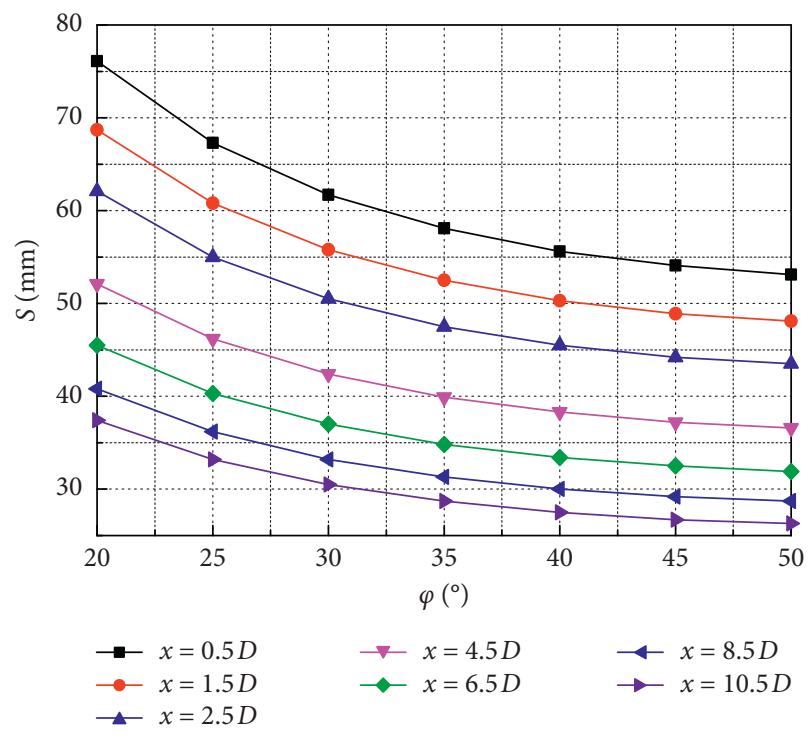

Figure 15: $\varphi$-S curve under $P=1000 \mathrm{kN}$ and $\alpha=60^{\circ}$.

4.5. Effect of the Friction Angle. Figures 14 and 15 show the $\varphi-S$ curve under different conditions when $P=1000 \mathrm{kN}$. The pile settlement decreases with the increase of the friction angle and the decrease rate is related to the slope effect. When $\alpha=15^{\circ}$, the pile settlement varies less with $\varphi$; however, when $\alpha=60^{\circ}$, the pile settlement changes greatly with $\varphi$. As $\varphi$ increases from $20^{\circ}$ to $50^{\circ}$, the pile settlement decreases by $30 \%$, indicating that increase of slope angle enhances the effect of $\varphi$ on the pile settlement. However, under the same angle, with the change of $x$, the rate of the pile settlement changing with $\varphi$ is basically the same, indicating that the effect of $\varphi$ on pile foundation settlement is almost not affected by $x$. 


\section{Conclusion}

Based on the hyperbolic curve tangent modulus method, this paper studies the calculation method of the pile settlement under vertical load in sloping ground, and conclusions are drawn as follows:

(1) Based on hyperbolic curve tangent modulus method, the calculation method of the pile settlement in sloping ground is proposed. The P-S curve obtained by this method is consistent with the numerical simulation results and the deformation law of the pile is consistent, which proves the feasibility of this method in calculating the pile settlement in sloping ground.

(2) The effect of the slope angle and the distance of the pile from the slope crest on the pile settlement is coupled. With the increase of $\alpha$, the effect of $x$ on the pile settlement is enhanced and, with the increase of $x$, the effect of $\alpha$ on settlement is weakened.

(3) The compression modulus, cohesion, and friction angle of the soil are all negatively related to the pile settlement. It was found that the pile settlement changes more obviously with the compression modulus, indicating that the compression modulus has a more significant effect on the pile settlement.

\section{Nomenclature}

$\begin{array}{ll}b_{r}, b_{q}, b_{c}: & \begin{array}{l}\text { Correction factor of foundation bottom tilt } \\ c:\end{array} \\ d_{r}, d_{q}, d_{c}: \begin{array}{l}\text { Cohesion of soil } \\ \text { Depth correction factor considering soil } \\ \text { strength }\end{array} \\ D: & \text { Pile diameter } \\ E_{s}: & \text { Compression modulus } \\ E_{t}: & \text { Tangent modulus } \\ E_{0}: & \text { Initial tangent modulus } \\ g: & \text { Acceleration of gravity } \\ g_{r}, g_{q}, g_{c}: & \text { Correction factor of ground tilt } \\ H: & \text { Pile length } \\ i_{r}, i_{q}, i_{c}: & \text { Correction factor of load inclination } \\ I_{p}: & \text { Stress influence coefficient of pile tip resistance } \\ I_{s}: & \text { Stress influence coefficient of pile side friction } \\ N_{q}, N_{c}, N_{r}: & \text { Bearing capacity coefficient of foundation } \\ P: & \text { Vertical load } \\ P_{u}: & \text { Ultimate resistance of pile tip } \\ P_{z}: & \text { Additional stress of soil at pile tip } \\ P_{z p}: & \text { Additional stress caused by pile tip resistance } \\ P_{z s}: & \text { Additional stress caused by pile side friction } \\ q: & \text { Self-weight stress of soil at pile tip } \\ R_{f}: & \text { Failure ratio } \\ S: & \text { Settlement of pile top } \\ s_{r}, s_{q}, s_{c}: & \text { Correction factor of pile foundation shape } \\ x: & \text { Distance of the pile from the slope crest } \\ \alpha: & \text { Slope angle } \\ \beta: & \text { Opposite angle of the slope angle } \\ \gamma: & \text { Bulk density of soil at pile tip } \\ \rho: & \text { Soil density } \\ \varphi: & \text { Friction angle of soil } \\ & \end{array}$
$v$ :
Poisson's ratio
$\delta:$
Tip resistance ratio.

\section{Data Availability}

The data used to support the findings of this study are available from the corresponding author upon request.

\section{Conflicts of Interest}

The authors declare that there are no conflicts of interest regarding the publication of this paper.

\section{Acknowledgments}

This work was supported by the National Natural Science Foundation of China (Grant no. 51678570).

\section{References}

[1] J. Q. Mao and Y. Jiang, "Settlement calculation of pile group foundation based on results of vertical static load test on single pile," Journal of the China Railway Society, vol. 39, no. 1, pp. 97-103, 2017.

[2] H. G. Poulos and E. H. Davis, Piles Foundation Analysis and Design, Wiley, New York, NY, USA, 1980.

[3] H. G. Poulos and E. H. Davis, "The settlement behaviour of single axially loaded incompressible piles and piers," Géotechnique, vol. 18, no. 3, pp. 351-371, 1968.

[4] R. W. Cooke, "The settlement of friction pile foundation," in Proceedings of the Conference of Tall Building Kuala Lumpur, Kuala Lumpur, Malaysia, 1974.

[5] H. B. Seed and L. C. Reese, "The action of soft clay along friction piles," Transactions, ASCE, vol. 122, no. SM11, pp. 731-754, 1957.

[6] L. Li and W. B. Gong, Prediction of Nonlinear Vertical Settlement of a Pile Group Consisting of New and Existing Displacement Piles in Clay Strata, Soils and Foundations, Tokyo, Japan, 2019.

[7] Y. Jia, F. G. Song, B. L. Wang, and L. C. Long, "Modified load transfer method for calculation of foundation pile settlement due to dewatering," Rock and Soil Mechanics, vol. 36, no. 1, pp. 68-82, 2015.

[8] W. J. Jun, D. Y. Yan, M. M. Wang et al., "Load-settlement rules and calculation of foundation piles in Karst cave, Chinese," Journal of Geotechnical Engineering, vol. 39, no. S2, pp. 67-70, 2017.

[9] M. H. Zhao, Y. Q. Yang, P. B. Yin, and J. Long, "Settlement calculation of pile foundation with elevated caps by energy method," Journal of Central South University (Science and Technology), vol. 46, no. 2, pp. 670-675, 2015.

[10] Q. Q. Zhao, R. F. Feng, Y. L. Yu, S. W. Liu, and J. G. Qian, Simplified Approach for Prediction of Nonlinear Response of Bored Pile Embedded in Sand, Soils and Foundations, Tokyo, Japan, 2019.

[11] M. H. Zhao, S. Q. Ma, Y. Xiao, and C. W. Yang, "Calculation on settlement of geogrid-encased stone columns based on thick-walled cylinder model," Journal of Hunan University (Natural Sciences), vol. 46, no. 5, pp. 86-93, 2019.

[12] D. D. Xin, L. W. Zhang, and C. X. Su, "Settlement research of pile groups in layered soil based on virtual soil-pile model," Rock and Soil Mechanics, vol. 38, no. 8, pp. 2368-2394, 2017. 
[13] Z. J. Wang, X. Y. Xie, and J. C. Wang, "A new nonlinear method for vertical settlement prediction of a single pile and pile groups in layered soils," Computers and Geotechnics, vol. 45, pp. 118-116, 2012.

[14] H. Sharafi, Y. S. Maleki, and M. K. Fard, "Three-dimensional finite difference modeling of static soil-pile interactions to calculate $\mathrm{p}-\mathrm{y}$ curves in pile-supported slopes," Arabian Journal of Geosciences, vol. 9, no. 1, pp. 1-16, 2016.

[15] K. S. Beena, P. E. Kavitha, and K. P. Narayanan, "Model studies on laterally loaded piles in sloping clay bed," Indian Geotechnical Journal, vol. 48, no. 5, pp. 1-11, 2017.

[16] Z. Fu, G. Jiang, S. Yuan, and A. Li, "Lateral behavior of piled bridge foundation and stabilizing piles on steep slope," KSCE Journal of Civil Engineering, vol. 23, no. 10, pp. 4223-4236, 2019.

[17] C. Jiang, Z. C. Zhao, and J. L. He, "Nonlinear analysis of combined loaded rigid piles in cohesionless soil slope," Computers and Geotechnics, vol. 117, 2020.

[18] Z. Muszyński and J. Rybak, "Horizontal displacement control in course of lateral loading of a pile in a slope," IOP Conference Series: Materials Science and Engineering, vol. 245, no. 3, Article ID 032002, 2017.

[19] N. Nimityongskul, Y. Kawamata, D. Rayamajhi et al., "Fullscale tests on effects of slope on lateral capacity of piles installed in cohesive soils," Journal of Geotechnical and Geoenvironmental Engineering, vol. 144, no. 1, Article ID 04017103, 2018.

[20] K. Georgiadis, M. Georgiadis, and C. Anagnostopoulos, "Lateral bearing capacity of rigid piles near clay slopes," Soils and Foundations, vol. 53, no. 1, pp. 144-154, 2013.

[21] M. H. Yang, B. Deng, and M. H. Zhao, "Experimental and theoretical studies of laterally loaded single piles in slopes," Journal of Zhejiang University-Science A (Applied Physics \& Engineering), vol. 20, no. 11, pp. 838-851, 2019.

[22] M. Jesmani, A. Kasrania, and M. Kamalzare, "Finite element modelling of undrained vertical bearing capacity of piles adjacent to different types of clayey slopes," International Journal of Geotechnical Engineering, vol. 12, no. 1, pp. 1-8, 2016.

[23] G. H. Yang, "New computation method for soil foundation settlements," Chinese Journal of Rock Mechanics and Engineering, vol. 27, no. 4, 2007.

[24] J. M. Gao and Z. L. Dun, Wedge Stress Theory and its Application in Engineering, Coal Industry Publishing House, Beijing, China, 2011.

[25] G. X. Li, B. Y. Zhang, and Y. Z. Yu, Soil Mechanics, Tsinghua University Press, Beijing, China, 2013.

[26] J. X. Zhou, G. X. Li, J. H. Zhang, S. M. Yu, and H. J. Wang, Foundation Works, Tsinghua University Press, Beijing, China, 2015.

[27] C. Jiang, J. L. He, L. Liu et al., "Effect of loading direction and slope on laterally loaded pile in sloping ground," Advances in Civil Engineering, vol. 2018, Article ID 7569578, 12 pages, 2018.

[28] P. D. Shi, Pile and Pile Foundation Handbook, China Communications Press Co., Ltd., Beijing, China, 2015. 